Virginia Commonwealth University VCU Scholars Compass

\title{
Nerve Conduction Through Dendrites via Proton Hopping
}

Lemont B. Kier

Virginia Commonwealth University

Follow this and additional works at: http://scholarscompass.vcu.edu/biol_pubs

Part of the Biology Commons

(C) 2017 Bentham Science Publishers

\section{Downloaded from}

http://scholarscompass.vcu.edu/biol_pubs/44

This Article is brought to you for free and open access by the Dept. of Biology at VCU Scholars Compass. It has been accepted for inclusion in Biology Publications by an authorized administrator of VCU Scholars Compass. For more information, please contact libcompass@vcu.edu. 


\section{Nerve Conduction Through Dendrites via Proton Hopping}

Lemont B. Kier*

Center for the Study of Biological Complexity, Institute for Structural Biology, Drug Discovery and Development, Virginia Commonwealth University, Richmond, VA 23298, USA

A R T I C L E H I S T O R Y

Received: December 04, 2015

Revised: June 22, 2016

Accepted: June 30, 2016

$10.2174 / 15734099126661607251132$ 33

\begin{abstract}
Background: In our previous studies of nerve conduction conducted by proton hopping, we have considered the axon, soma, synapse and the nodes of Ranvier. The role of proton hopping described the passage of information through each of these units of a typical nerve system. The synapse projects information from the axon to the dendrite and their associated spines.
\end{abstract}

Methods: We have invoked the passage of protons via a hopping mechanism to illustrate the continuum of the impulse through the system, via the soma following the dendrites. This is proposed to be a continuum invoked by the proton hopping method.

Results: With the proposal of the activity through the dendrites, via proton hopping, a complete model of the nerve function is invoked. At each step to the way, a water pathway is present and is invoked in the proposed model as the carrier of the message via proton hopping. The importance of the dendrites is evident by the presence of a vast number of spines, each possessing the possibility to carry unique messages through the nervous system.

Conclusion: With this model of the role of dendrites, functioning with the presence of proton hopping, a complete model of the nerve system is presented. The validity of this model will be available for further studies and models to assess it's validity.

Keywords: Dendrites, neuron conduction, neurons, node of ranvier, proton hopping, synapse.

\section{INTRODUCTION}

In our development of the theory of proton hopping being the mechanism of nerve conduction, we have focused on several neuron structures to illustrate this process. Our first study was a model of information flow down a channel [1]. The second study, modeled the myelinated axon action potential via proton hopping [2]. The third study was a model of a synapse encounter of an effector and a ligand, producing a proton hopping event [3]. A recent study, employing the theory of proton hopping, was a model of this process over the surface of a soma, with emphasis on the role of the protein surfaces available on the soma, to create a water wire guiding the proton hopping over the surface [4]. Another study is a model of proton hopping through the nodes of Ranvier, influenced by the $\mathrm{Na}^{+}$and $\mathrm{K}^{+}$ions in that system of the axon [5]. In more detail, the proton hopping through spaces simulating aqua channels and the periaxonal space separating the axon from the myelin sheath, were conducted using cellular automata models to simulate the virtual proton passage [6]. This simulated the effect of width of space

\footnotetext{
*Address correspondence to this author at the Center for the Study of Biological Complexity, Institute for Structural Biology, Drug Discovery and Development, Virginia Commonwealth University, Richmond VA 23298 USA; E-mail: lbkier@vcu.edu
}

influencing proton hopping passage through these systems. These results correlated with the observation that unmyelinated axons exhibit a much slower flow of information in such a neuron.

\section{DENDRITES}

An important functional part of a neuron occurs in the area of systems known as dendrites and their associated structures known as spines, Fig. (1). These systems are located between the nerve synapse and the soma, and they carry the impulse of information through that area. The structures and functions of this system are reviewed [7-9]. The dendrites are branched structures off of the soma. The branching varies in extent, location and structure. The branched variation is associated with different functional characteristics of the neuron of which they are a part. The dendrites principal function is to receive signals from the synapses associated with a neighboring nerve cell and to pass this along to the soma to which they are attached. The signal has earlier been described to be electronic conduction.

The branching along the dendrites are the presence of out-growths called spines. Their number on any dendrite can vary widely. These spines are relatively small compared to the dendrite they are associated with. The dendritic spine is the structural feature that receives the information input 


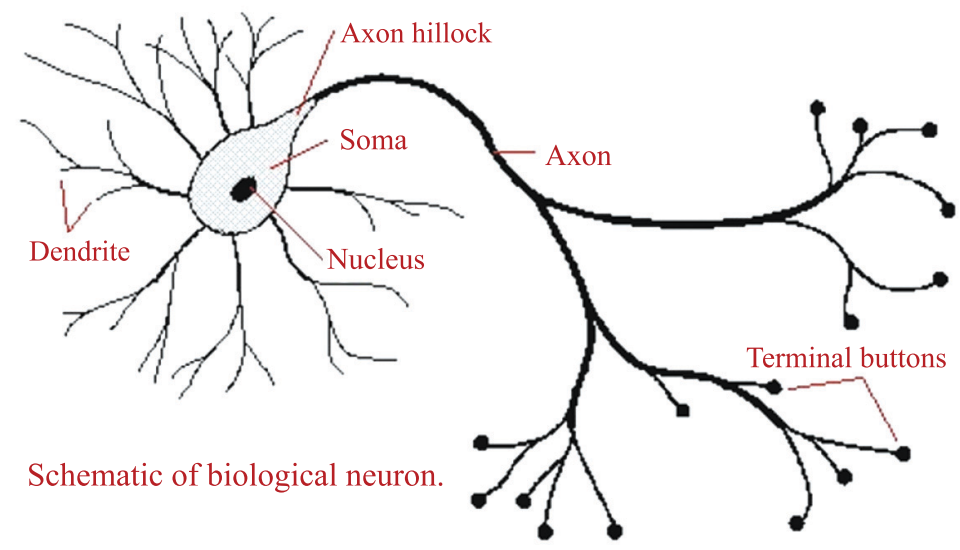

Fig. (1). The Dendrites in the Neuron

through a nearby synapse associated with a neighboring axon. The synaptic potentials in any dendrite are relatively fast due to the small capacitance of the spines. The structure and the number of spines on a dendrite produces a higher capacitance on the dendrite. Thus the dendritic system plays a significant role in the passage of information from one axon to the next in a neuron system.

\section{PROTEINS IN DENDRITES AND SPINES}

A number of actin- binding proteins have been implicated in dendrite and spine function [10-12]. The length of spines relates to protein presence, hence to their function and stability. A detailed summary of the roles of proteins here is found in a review [9]. One important role of proteins in neuron systems such as the dendrites and their spines, is their roles in providing surface side chain pathways that influence surface water. This creates water pathways, water wires, that can facilitate information flow. This is the proposal that information from the synapse through the dendrite-spine system to the soma proceeds via proton hopping. An essential encounter for proton hopping through a defined passage is the presence of water in an organized system. Such a system depends on the organization of water, which can be created by the systematic influence of amino acid side chains on a protein surface. This is a role for proteins in the dendritespine systems.

\section{PROTON HOPPING}

Within the axon are ion channels that permit the flow of sodium and potassium ions through the axon surface, in and out to the interior of the cell. The flow of information along the axon, called the action potential, has been ascribed to the flow pattern, in and out of the of the axon cell, of sodium and potassium ions. Action potentials travel at speeds along the axon, of $150 \mathrm{~m} / \mathrm{s}$ in axons that are sheaved by a structure of myelin. Diffusion of water, $\mathrm{Na}^{+}$or $\mathrm{K}^{+}$ions is far too slow to be invoked as the carrier of the information passing along the axon, through the synapse, to the next axon beyond.

From this background of knowledge of neuron function, action potential and information passage, a new theory of the mechanism of information transport in a neuron, emerged [2]. That theory is built around the phenomenon of proton hopping, described by Grotthuss in 1806 [13]. He envisioned the virtual passage of a proton through bulk water. The process is termed virtual since it is not the same proton passing through the water. It is an exchange of the hydrogen bonding of a proton from a water molecule, to another oxygen of a neighboring water molecule, with the formation of a new covalent bond to that neighboring oxygen atom, leaving the former covalent bond as a hydrogen bond. Fig. (2) shows this event. The process repeats as the bonding exchange passes through the bulk water. Thus water under these circumstances has a conductive property. At the time of the publication of this theory by Grotthuss, the structure of water was considered to be HO. Several reviews describe this phenomenon [14-16].

Much has been learned about this process and it reveals remarkable phenomena for a simple 3-atom molecule. It has been observed that a minimum of $20 \%$ water in another substance, is necessary for the process to take place. Thus bulk water is the environment that makes the process possible. In fact, bulk water is really all that we know very much about. Single, isolated water molecules, called mono-water, are very much strangers to our current understanding. Proton hopping can only occur when the Gibbs energy of the system does not change with each transfer. Otherwise, ions would be trapped in a more stable state so that a transfer would not occur.

When compared with the diffusion of $\mathrm{H}_{3} \mathrm{O}^{+}$, proton hopping is vastly more rapid since it is such a very low energy process. Proton hopping is the fastest known chemical reaction. It has a velocity of about $1 \%$ of the velocity of the pas-

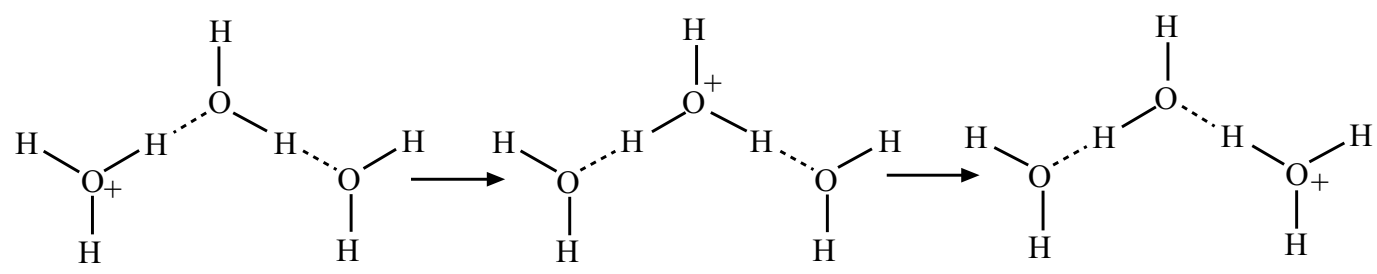

Fig. (2). Proton hopping. 
sage down an electrical wire. Proton hopping is faster in warmer water even though the cluster of water are less organized. In that case, the water clusters are less organized but they are more responsive to changing positions, leading to the presence of more passage ways for the hopping to occur.

From this background of our theory of proton hopping in nerve conduction systems, we extend the concept to propose that the nerve conduction through dendrites and spines, between the synapses and soma, is by the process of proton hopping. The proteins, so intimately involved in the functions of dendrites and spines [9, 17] carry on their surfaces the side chains that facilitate, through their hydropathic influences on near-by water, the creation of proton hopping paths, water wires, that facilitate and direct the axon potentials in nerve systems. Porter and Volrath [17] have focused attention on propagation of hydrated protons and have estimated a wave velocity of about $16 \mathrm{~m} \mathrm{~s}^{-1}$ deduced from the product of activation frequency and peptide segment length. This is the same order as nerve signal propagation velocity. We cannot specify the mechanism of information transfer by this mechanism but it might bear some relation to electric signals down a wire where the passage of an electron is also virtual, like the virtual passage in proton hopping. An alternative theory would invoke neuron specificity for each specific information element. These remain as subjects of further study.

The dendrite-spine system has been implicated in a number of diseases such as Alzheimers [18, 19], schizophrenia $[20,21]$, and autism and intellectual disabilities [22, 23]. The roles of dendrite and spine functional changes are heavily implicated in these analyses. With the proposal here of a proton hopping nerve information flow through these systems, a focus of attention on a better understanding and possible corrections and cures may unfold.

\section{CONFLICT OF INTEREST}

The author confirms that this article content has no conflict of interest.

\section{ACKNOWLEDGEMENTS}

Declared none.

\section{REFERENCES}

[1] Kier, L.; Tombes, R.; Hall, L.; Cheng, C. A cellular automata model of proton hopping down a channel. Chem. Biodiv., 2013, 10, 338-342.
[2] Kier, L.; Tombes, R. Proton hopping: a proposed mechanism for myelinated axon nerve impulses. Chem. Biodiv., 2013, 10, 596599.

[3] Kier, L.; Hall, L. The creation of proton hopping from a drugreceptor encounter. Chem. Biodiv., 2013, 10, 221-225.

[4] Kier, L.; Hall, L. A model of information carried over a neuron soma. Chem. Biodiv., 2016, 13, 238 .

[5] Kier, L.; Hall, L. Enhanced action potential passage through the node of Ranvier of myelinated axons via proton hopping. Curr. Comp. Aided Drug Des., 2015, 11, 5.

[6] Kier, L.; Seybold, P.; Cheng, C. Cellular automata modeling of chemical systems. Springer: Dorderecht, Netherlands, 2005.

[7] Nimchinsky, B.; Sabatini, B.; Svoboda, K. Reduced dendritic spine density in auditory codex of subjects with schizophrenia. Ann. Rev. Physiol., 2002, 64, 374-389.

[8] Tavosanis, G. Dendritic structural plasticity. Devel. Neurobio., 2002, 72, 73-86.

[9] Sala, C.; Segal, M. Dendritic spines: The locus of structural and functional plasticity. Physiol. Revs., 2014, 94, 141-188.

[10] Biou, V.; Brinkhaus, H.; Malenka, R.; Matus, A. Interactions between drebrin and RAS regulate dendritic spine plasticity. Eur. $J$. Neurosci., 2008, 27, 2847-2859.

[11] Hayashi, K.; Shirao, T. Change in the shape of dendritic spines caused by overexpression of debrin in cultured cortical neurons. $J$. Neurosci., 1999, 19, 3918-3925.

[12] Mizui, T.; Takahshi, H.; Sekino, Y.; Shirao, T. Overexpression of dobrin $\mathrm{A}$ in immature neurons induces accumulation of F-actin and PSD-95 into dendrite filopodia, and the formation of large abnormal protrusions. Mol. Cell Neurosci., 2005, 30, 149-157.

[13] Grotthuss, C. Sur la decomposition de l'eau et corps qu'elle tient en dissolution a l'aide de l'electricie galvanique. Ann. Chim., 1806, 58, 54-58.

[14] Kornyshev, A.A.; Kuznetsov, E.; Spohr, J.; Ulstrup, J. Kinetics of proton transport in water. J. Phys. Chem. B., 2003, 107, 3351-3366.

[15] Agmon, N. The Grotthus mechanism. Chem. Phys. Lett., 1995, 244 , 456-462.

[16] Gileadi, E.; Kirowa-Eisner, E. Electrolytic conductivity - the hopping mechanism of the proton and beyond. Electrochim. Acta., 2006, 51, 6003-6011.

[17] Porter, D.; Volrath, F. Water mediated proton hopping empowers proteins. Soft Matter, 2013, 9, 643-646.

[18] Marcello, E.; Epis, R.; Saraceno, C.; Luca, M. Synaptic disfunction in Alzheimers disease. Adv. Exp. Med. Biol., 2012, 970, 573-601.

[19] Yu, W.; Lu, B. Synapses and dendritic spines as pathogenic targets in Alzheimers disease. Nural Plast., 2012, 247150.

[20] Sweet, T.; Henteleff, R.; Zhang, W.; Sampson, A.; Lewis, D. Reduced dendrite spine density in auditory codex of subjects with schizophrenia. Neuropsychopharmacology, 2009, 34, 374-389.

[21] Yoshida, T.; McCarley, R.; Lee, K.; Bouix, S.; Salisbury, D.; Morra, L.; Shaenton, M.; Niznikiewicz, M. A prospective longitudinal volumetric MRI study of superior temporal gyrus gray matter and amygdala-hippocampal complex in chronic schizophrenia. Schizophr. Res., 2009, 113, 84-94.

[22] Hutsler, J.; Zhang, H. Increased dendritic spine densities on cortical projection neurons in autism spectrum disorders. Brain Res., 2012, 1309, 83-94.

[23] Valnegri, P.; Sala, C.; Passafaro, M. Synaptic dysfunction and intellectual disability. Adv. Exp. Med., 2012, 970, 433-449. 